\title{
UNIVERSO PARTICULAR, A ARTE COMO MEDIADORA DE REALIDADES E IDENTIDADES
}

\author{
Vanessa Schultz ${ }^{1}$ Luana M. Veiga ${ }^{2}$
}

PALAVRAS-CHAVE: Identidade; Exposição; Design gráfico; Tercília dos Santos

RESUMO: O texto analisa as relações de identidade cultural, produção plástica, opção de curadoria e características da peça gráfica da exposição A Casa de Tercília, da artista Tercília dos Santos.

Tercília inventa seu lar a cada dia. Sua casa é antes de tudo uma idéia, um sonho de pertencimento. Toda manhã, ela parece acordar para um mundo desértico, fechado e excludente. E para enfrentar a áspera superfície das estruturas sociais sedimentadas em séculos de preconceito e desigualdade, Tercília fecha a escotilha de sua cápsula de esperança. (LINDOTE, 2005, p. 1)

Mulher, agricultora, negra, pobre. Dessas condições iniciais desenvolve-se a vida e a produção plástica de Tercília dos Santos. A mulher do meio rural torna-se urbana, busca substituir as impossibilidades que a roça oferecia por outras formas de conhe-cimento, grupos sociais, jeitos de expressar a espiritualidade. Todas essas possi-bilidades em contato com o universo interior - com seus conflitos, angústias, medo e sabedoria - eclodem como nova linguagem: a expressão artística.

De acordo com Stuart Hall, a velocidade vertiginosa das mudanças estruturais e institucionais na pósmodernidade tornou o próprio processo de identificação mais provisório, variável e problemático.

A identidade torna-se uma "celebração móvel": formada e transformada continuadamente em relação às formas pelas quais somos representados ou interpelados nos sistemas culturais que nos rodeiam É definida historicamente, e não biologicamente.

O sujeito assume identidades diferentes em diferentes momentos, identidades que não são unificadas ao redor de um "eu" coerente. (HALL, 1987, p.13)

Como artista, agora oficialmente reconhecida, sua obra é oferecida ao público como extensão material daquilo que lhe é íntimo, cotidiano, corporal: uma ambientação de parte de sua casa. O espaço é todo ocupado por ela, pinturas, toalhas de mesa, almofadas, tapete e panneaux vestem paredes, chão, sofás, mesa e cadeiras, e comuni-cam o imaginário da artista. Para completar a mediação público-obra um workshop /chá da tarde, com Tercília, também acontece no ambiente.

Para acompanhar a mostra foi produzido um catálogo, que procura traduzir para a mídia dos papéis impressos a intensidade do processo desta vida, sua identidade - ora única, ora múltipla -, a forma encontrada para harmonizar coerências e incoerências e aceitar aquilo que não se harmoniza.

\section{Mulher entre as mulheres}

${ }_{1}^{1}$ Mestranda do PPGAV-CEART, orientadora: ReginaMelim
${ }^{2}$ Mestranda do PPGAV-CEART, orientadora: Yara Guasque. 
Quinta filha de uma prole de seis meninas, Tercília dos Santos nasceu em 8 de feve-reiro de 1953, em Piratuba, oeste de Santa Catarina. Numa região de colonização européia, sua família era a única afrodescendente. Possuíam um minifúndio que produzia para a subsistência e que foi hipotecado várias vezes em decorrência dos problemas de saúde na família. A dinâmica da vida social refletia o preconceito da comunidade, a família era chamada para ajudar nos mutirões e esquecida nas festas - a não ser que prestasse algum serviço -, sendo assim, a igreja era o único compromisso social tolerado.

Depositária da confiança do pai na coordenação das tarefas domésticas após o falecimento da mãe, a menina entrava em conflito com as irmãs, com quem dividia as tarefas, mas não o desejo de mudança.

Tercília tinha um segredo: queria ir à escola.

Era uma época em que os negros não podiam dançar em "baile de branco". E era uma época em que as outras crianças se negavam a brincar de roda com ela.

Nessa época, sem o consentimento do pai, matriculou-se na escola isolada, aonde ia a cavalo, todos os dias, por muitos e muitos quilômetros.

Ela acordava de madrugada para estudar à luz do fogão a lenha.

A menina de onze anos descobria nos estudos o caminho para alcançar outro sonho: sair da cidade em que nasceu. (RADÜNZ, KLAMT, 2005, p. 1)

Aos quinze anos deixou a terra natal, trabalhou como doméstica em diversas cidades até chegar a Florianópolis. Permaneceu doméstica para ter tempo de retomar os estudos. Tornou-se manicura, profissão que exerceu por quase vinte anos.

Autonomia para pagar o aluguel da sua casa ela conseguiu com a ajuda das amizades que fez ao longo do tempo, e a partir da vontade de comprar quadros para enfeitar as paredes de casa veio a orientação espiritual': "- Você não precisa comprar quadros dos outros, pode ter os seus próprios."

Tercília dormiu, sonhou ${ }^{4}$ acordou pintora.

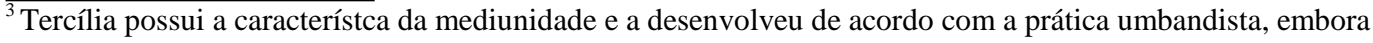
continue a praticar o catolicismo, diz ela: "A religião que a gente tem não é religião, é um dom, é uma afinidade espiritual que a gente tem com os espírtos, eles precisam vir a terra para ajudar as pessoas e a gente serve a eles como instrumento, eles mesmos pedem para a gente ir a igreja. ” Depoimento concedido em 14.05.1994 para a monografia Tercília dos Santos - Trabalho de Aproveitamento da Disciplina de Evolução das Artes Visuais do Curso de Licenciatura em Educação Artística com Hablilitação em Artes Plásticas da Universidade do Estado de Santa Catarina, realizada por Cláudia Pierdoná, José Carlos Kroth, Marilin Vieira, Nádia Juppe e Vanessa Cristiane Schultz, p. 15.

${ }^{4}$... nesta mesma noite Tercília teve dois sonhos. O primeiro foi com um quadro que era uma revoada de pombos, apesar de se referir a uma pintura a cena era animada. O segundo sonho era o massacre de Jesus Cristo, mas esta imagem estava em segundo plano, o plano principal era uma passagem da terra para o céu, onde passavam mulheres com vestes de colorido intenso. No dia seguinte Tercília sentiu a necessidade de pintar e pintou compul-sivamente os dois sonhos. Idem, p. 2
} 


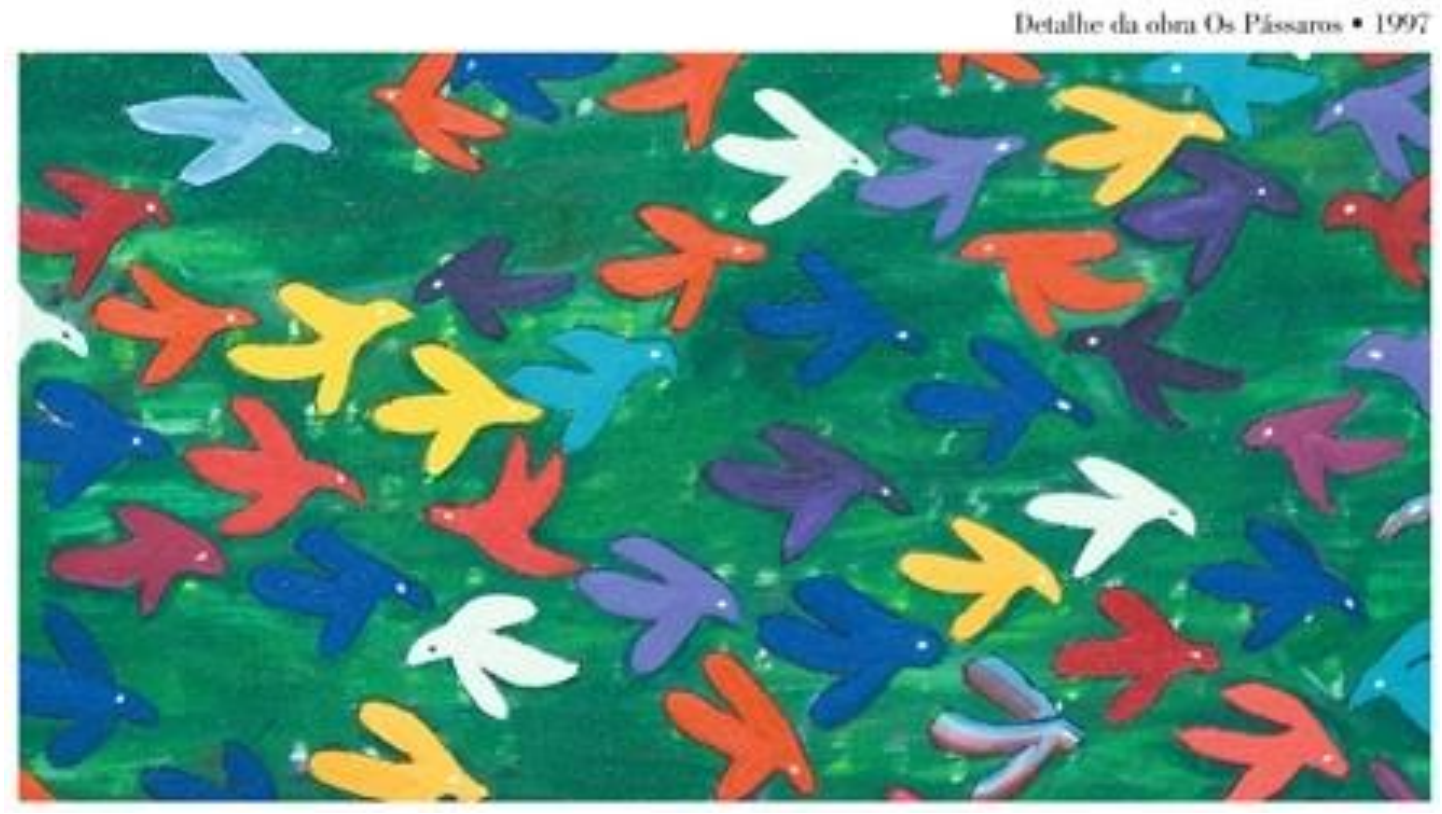

\section{Da limitação à possibilidade de caos}

A vida no meio rural oferecia o apreciado contato com a natureza, mas também limitava as possibilidades de troca de conhecimento e de uma vida menos segregadora. A saída voluntária desta realidade a leva a outra condição, já que

A cidade é um sistema semiótico, um modo de vida de produção e consumo de mercadorias e códigos; nasce da necessidade das trocas dessas mercadorias - bens materiais - e dos códigos - informações trocas simbólicas. É assim, um território organizado para estabelecer a comunicação, isto é, tornar comuns os bens privados - materiais - e as ideologias e os sonhos. (RAMOS, 2006)

Possibilidade de identificação de semelhantes e outros tipos de contato social, a cidade se apresenta à artista como único lugar em que se pode contemplar o mundo com a esperança de produzir um futuro (SANTOS, 2002, p. 71). Mesmo assim, continuam a acompanhá-la as dificuldades decorrentes da pobreza, da condição do gênero feminino e de sua cor.

Defensora do feminismo, a condição social da artista não permite que desfrute de muitas das benesses por ele proporcionadas, pois, não foi, ou é, um movimento que faz parte da vida das mulheres de forma igualitária, segundo Alison Wolf, ele sempre foi

“... um movimento desonesto. Ele se apresenta como um movi-mento que defendia o interesse de todas as mulheres, mas era voltado a uma minoria de mulheres da elite, mas com um discurso de que todas as mulheres são iguais e querem as mesmas coisas."

A autora ainda diz que

“... é estúpido se referir às mulheres como se elas fossem todas iguais - ninguém se refere aos homens como se eles fossem todos iguais. Longe de formarem um grupo homogêneo, as mulheres se dividem em dois grupos de forma dramática: as educadas, que buscam uma carreira em detrimento da dedicação à família, e as não-educadas, que se dedicam à família por falta de opção." (WOLF, 2006) 


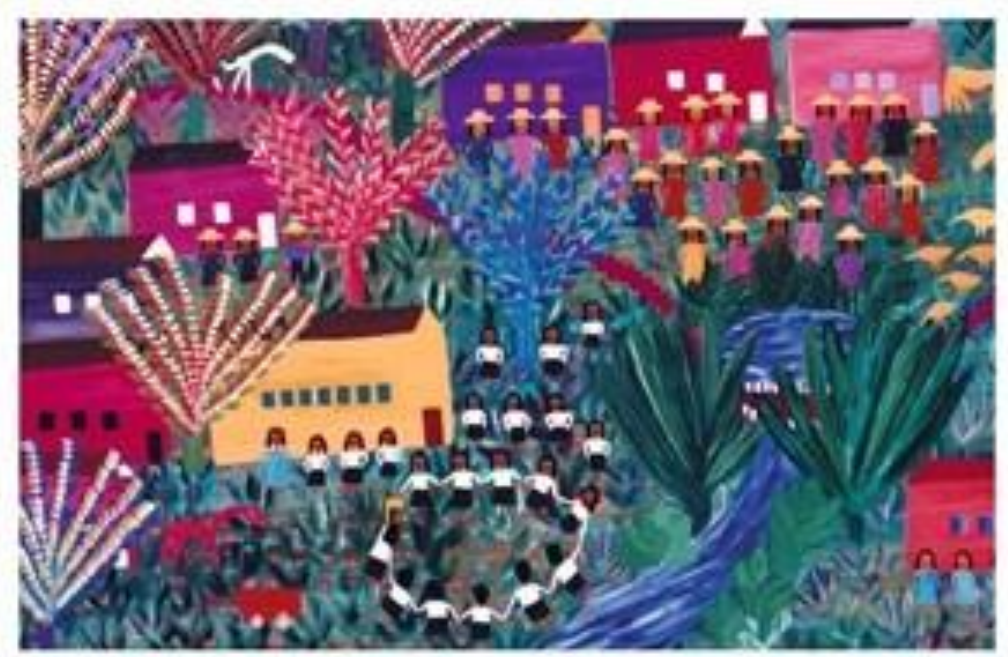

Detallhe da obra As Feministas ot 2 - 1909

Como um barco a deriva num mar de generalizações, solteira, sem filhos e com pouca educação, a artista encara a realidade do mundo capitalista, onde o que está fora do mercado não tem valor. A arte surge então como forma de sobrevivência econômica e simbólica. Transformando o indeterminado em determinado através das forças criadoras, a artista passa à tentativa de harmonização de sua realidade, materializando e dando significado a seus desejos, quereres, tudo aquilo que lhe é precioso, através da linguagem da pintura. Os temas são a natureza e a vida rural, a união das raças, o feminismo e questões espirituais.

Construção de um mundo, o processo de trabalho de Tercília obedece a uma hierarquia natural. Suas pinturas começam pela terra, vermelha e fértil que cobre toda a tela, depois, e nessa ordem, gramíneas e vegetação de pequeno, médio e grande porte, animais, pessoas e suas habitações. O processo construtivo se repete nas casas, que têm inicialmente pintadas as vigas estruturais e posteriormente telhado, paredes, portas e janelas.
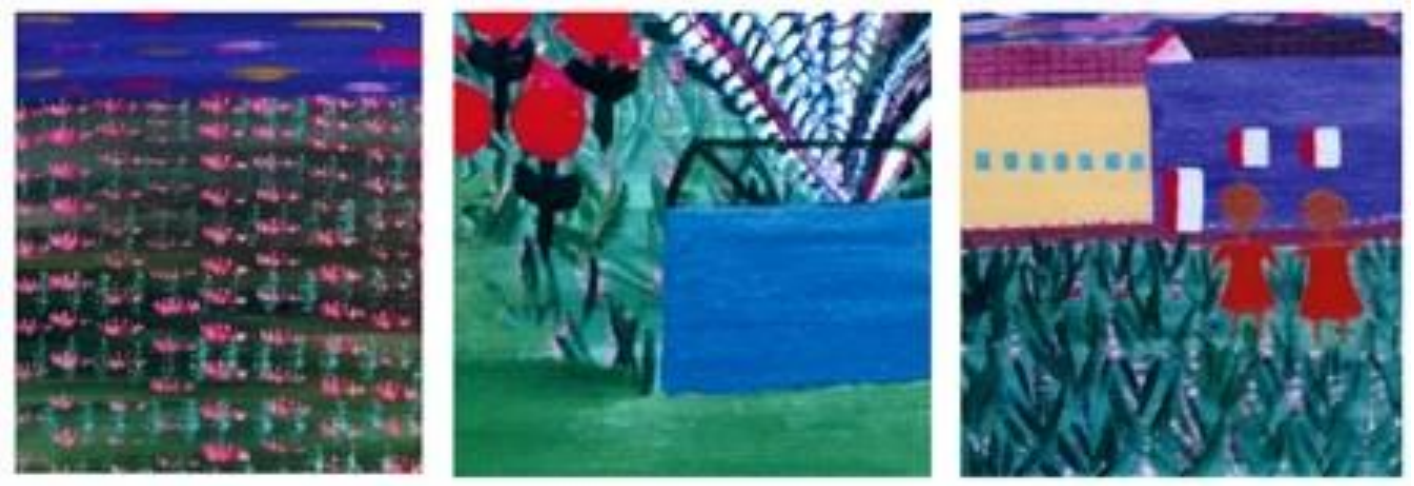

Detalbes de diras em proesso

A problemática racial transformou-se rapidamente no universo pictórico da artista, seus primeiros quadros - como Começando o Dia, de 1990 - não traziam afro-descendentes, com a exposição destes e o estabelecimento de uma troca de informa-ções/comunicação com seu público, que começou a questionála a este respeito, começaram a surgir pinturas como A União das Raças, de 1991, e uma gradual mistura de tons de pele. Também ocorreu uma radicalização, com quadros de persona-gens exclusivamente negros, como em O Trabalho Mirim, de 1993. Cabelos loiros não são mais vistos nas suas telas e agora ela pratica uma paleta de tons de pele que não sofre mais branqueamento total. 

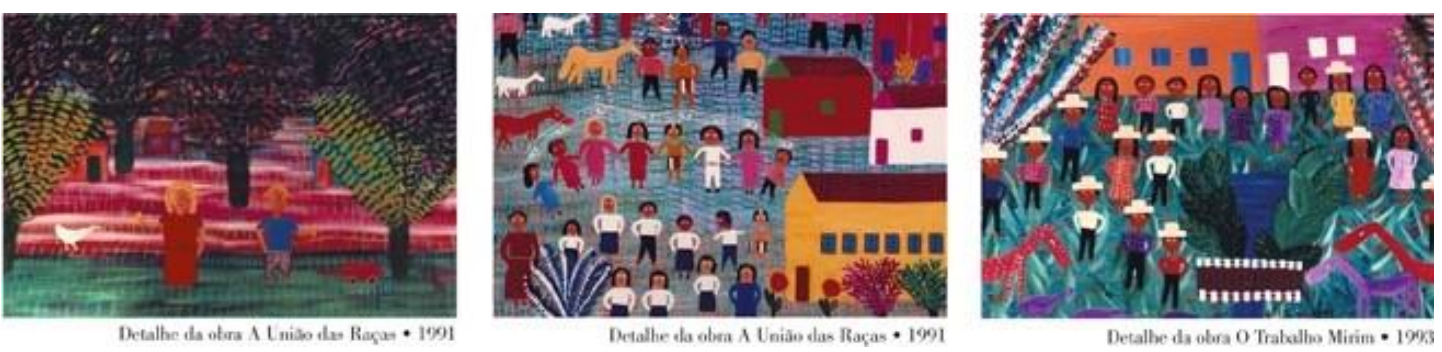

O fazer artístico oferece uma liberdade até então não experimentada, após receber orientação de outro artista, Tercília se dá conta de que na pintura não existe erro, porque pode existir árvore com raiz para cima e copa de cabeça para baixo. (RADÜNZ, KLAMT, 2005, p. 21)

Representada por uma arte hegemônica, surge então para ela uma nova possibilidade de identidade, o status de artista - rapidamente reconhecida pelo sistema da arte - a coloca numa situação social antes impossível. O novo status confere também um novo mercado, aonde sua valoração se dá pela capacidade criadora. Pessoas novas e outras opções de aprendizado entram em contato com o seu mundo, agora literalmente visível.

Fazendo um caminho inverso em relação a maioria dos artistas populares, a poética de Tercília migrou também para o artesanato, que também faz parte da renda que lhe garante a subsistência. Caminho rebatido, tapetes, almofadas, toalhas e panneaux agora participam de sua obra artística. A respeito da relação entre arte popular e artesanato Roberto Rugiero diz:

O artesanato embasado na tradição é visto como parte da arte popular, sem dúvida. Mas ele é funcional, tem uma finalidade e uma repetição características. Existe, porém, algo intermediário que é o artesanato artístico, muito rico no Brasil. É que dentro do artesanato existem peças de qualidade plástica tão elevada, tão refinada, que há nelas uma função poética, a presença de uma mão emotiva na sua confecção. Ticio Escobar, historiador paraguaio, elucida que na medida em que a função prevalece sobre a forma, estamos diante de artesanato. Quando a forma se sobrepõe à função, é arte. (RUGGIERO, 2005, pp. 86-88)

Base simbólica fixa de sua material móvel vida, apesar de sempre ser moradia alugada, a casa de Tercília causa impacto.

Já visitei outras casas da Casa de Tercília e, por mais improvável que pareça, ela é sempre igual. Nesta de agora, não cheguei a ouvir as crianças dos vizinhos da mais antiga. A anterior parecia divinhar a sacada que esta possui. De outras só ouvi falar. Mas estão sempre lá: a mesa central com suas toalhas engomadas, as frutas sobre elas, o quarto pequeno e austero como a cela de uma freira, a sala repleta das imagens de sua pintura. (LINDOTE, 2005, p. 21)

Síntese/exemplo de um processo de elaboração de uma linguagem artística particular, a casa passa a ser a própria obra, sempre em construção e adaptação a realidade.

\section{O projeto gráfico como linguagem complementar}

Um trabalho de desenho gráfico atende a necessidades diversificadas, limites práticos /orçamentários bem delimitados e agrega poéticas que se fazem tradutoras da poética inicial. Complementando a opção curatorial, como catálogo foi feita uma peça que usou como referências o livro e cadernos de receitas culinárias. $\mathrm{O}$ primeiro se justifica pela forma narrativa em que o texto literário foi elaborado e a disposição das imagens - reproduções das obras que compõe a exposição e imagen da casa da artista - de forma ilustrativa em relação a ele. $\mathrm{O}$ segundo para fazer relação à casa idealizada pela artista, que segue as normas de etiqueta e do "bem receber". 
Fio condutor de um outro texto, visual/conceitual, que perpassa todo o catálogo foi a questão cromática/racial, que, além das obras, foi inspirado nas seguintes frases presentes na publicação:

Tercília tem a lição da cor em sua pele. E transforma esse aprendizado na força que movimenta seu pincel.

A Casa de Tercília estará sempre em algum lugar esperando por nós. À esquerda do coração, passando a vendinha da Dona Felicida-de, logo depois da pracinha da Humildade - por ali, entre flores e folhagens vivem Tercília e seus amigos de cor. (LINDOTE, 2005, pp. 21)

A partir deste princípio há nas contra-capas duas fotografias em close de parte do rosto da artista, é preciso fechar os olhos para adentrar neste universo particular, que, ao se despedir os abre devolvendonos ao mundo exterior, ao passarmos pela contra-capa final. Fica ainda a intenção de que, ao nos fazermos imagem olhada pela artista, parte de nós pode naquele mundo morar.

Fomentando a discussão de forma poética, o catálogo é todo composto com a intercalação de páginas de papel branco revestido13 (impresso em policromia) e papel "não branco" e sem revestimento (impresso em monocromia-preto). As páginas em papel branco contém o texto literário e as imagens que o ilustram. As páginas no papel "não branco" tem uma escala de pigmentação em 4 etapas, do marfim ao preto na primeira metade da publicação e do preto ao marfim na segunda metade, sempre com a mesma textura monocromática que deriva da imagem colorida usada na capa. O objetivo é ilustrar uma questão muito simples em relação a cor da cútis humana: nenhum ser humano dito branco de fato o é, bem como não existe nenhum preto. Soma-se a questão mocromática a escolha proposital de um papel não revestido para estimular uma sensação agradável ao toque das mãos nessas páginas.

Cabe ainda dizer que foi escolha proposital da direção de arte mostrar, nas páginas centrais - que intencionalmente não possuem a interferência das páginas monocro-máticas de papel pigmentado - frente e verso do tapete que é parte da mostra, reflexão condicionada ao fato de que todos nós, humanos brancos, pretos, azuis, amarelos e os que refletem as cores do arco-íris, virados do avesso obedecemos sem distinção alguma aos tons de vermelho.

\section{Considerações finais}

A exposição A Casa de Tercília mostra através da sua obra como um único ser humano contemporâneo pode ter em si múltiplas identidades, que podem agir sozi-nhas ou em interpolação, em resposta a velocidade das mudanças do mundo globalizado e aos lugares que objetivamente ocupamos no mundo social e cultural. Estas identidades não necessariamente se complementam, podem ser contraditórias e não se resolverem.

Nem todo mundo vive na mesma realidade, ao sair da cidade natal a artista buscou o conflito, a sociabilidade, trocas limitadas na sua vida até então, uma outra realidade.

Como artista, as possibilidades experimentadas por ela não se limitam ao ser humano, alcançam a natureza como um todo. Cria um universo que faz referência ao que já foi seu, mas existe - enquanto obra - como deveria ter sido, como pode ser e não como foi. A arte é para Tercília a tentativa de junção dessas realidades, de harmonização ideológica e emocional das contradições e, talvez, de busca de mais uma nova realidade.

\section{BIBLIOGRAFIA}

LINDOTE, Fernando. A Casa de Tercília, Florianópolis, SESC-SC, 2005.

HALL, Stuart. Identidade Cultural na Pós-modernidade, Rio de Janeiro, RJ, 2005.

RAMOS, Célia M. Antonacci. Poéticas do Urbano - Ponto de Partida, in:

www.ceart.udesc.br/poeticasdourbano.

DAPesquisa, Florianópolis, v.2, n.4, p. 169-175, 2007. 
SANTOS, Milton. O País Distorcido, Publifolha, 2002.

WOLF, Alison. 'Liberdade Vigiada' in Folha de São Paulo, caderno Mais!, 02/04/2006.

RADÜNZ, Dennis, KLAMT, Valdemir. O céu deveria ser azul, Florianópolis, SESC-SC, 2005.

RUGIERO, Roberto. 'Marchand da Resistência' in Revista Raiz, São Paulo, SP, 2006. 